\title{
Numerical Progressive Collapse Analysis of RC Framed Structures
}

\author{
Ahmad Shehada ${ }^{1}$, Said Elkholy ${ }^{1,2}$, Bilal El-Ariss ${ }^{1,3}$ \\ ${ }^{1}$ United Arab Emirates University \\ P.O.Box 1555, Al Ain, UAE \\ 201970261@uaeu.ac.ae; selkhouly@uaeu.ac.ae; bilal.elariss@uaeu.ac.ae \\ ${ }^{2}$ Fayoum University \\ P.O. Box 63514, Fayoum, Egypt \\ sak00@fayoum.edu.eg \\ ${ }^{3}$ corresponding author \\ bilal.elariss@uaeu.ac.ae
}

\begin{abstract}
Predicting reinforced concrete (RC) framed structure resistance to progressive collapse as a result of column removal scenario has recently become a necessity in the design of such structures. Such removal leads to large deformations impairing the functional performance of the structure. To predict the progressive collapse resistance, most of the researchers have developed numerical models to simulate the behaviour of test frames. However, these numerical models are confined to the test frames and would need to be modified when simulating different frames. This study discusses the resistance of RC framed structure to progressive collapse due to column exclusion from the viewpoint of numerical modelling issues using fibre element approach. The numerical results using fibre element approach were compared with a reported database of ten test RC framed buildings. The study shows that developing a simple numerical model, as an alternative to destructive tests, based on the fibre element approach with few elements and properly selected model parameters to adjust can accurately predict the resistance of structures subjected to interior column removal with minimal computational time and effort, and can be utilized in lieu of performing difficult advanced geometric and material nonlinear finite element computations.
\end{abstract}

Keywords: Progressive collapse; Fibre element approach; Numerical simulation; RC frame sub assemblages

\section{Introduction}

Progressive collapse of buildings due to failure of a local load carrying member has become a focus of attention recently due to the serious consequences associated with it. The spread of such a local failure could become disastrous and lead to casualties and destruction of properties. Several reviews have been reported in the literature dealing with building progressive collapse regulations and guidelines, proper detailing, and damaged area under different design loads [1-4]. In these reviews, numerous progressive collapse test and numerical evaluation procedures were discussed, and some recommendation for reinforced concrete, steel, and composite buildings were presented to assure robust behaviour of buildings after an unexpected loading. Guidelines and Building regulations [5-6] have been developed to prevent the spread of a local damage into disproportionate collapse. Moreover, numerous progressive collapse studies investigated the resistance of structures to abnormal loading, proposed mitigating techniques to preserve the load carrying capacity of the structures, or examined different load paths to redistribute the loads due to column removal.

Over the past decade, different approaches have been pursued to numerically and experimentally evaluate the strength of reinforced concrete structures under column removal scenarios. Finite element numerical models have been proposed to simulate and predict the experimental results from testing beam-column assemblies, beam-slab assemblies, multi-story frames, full scales, half scaled, third scaled 3D structures subjected to sudden failure. Lu et al. [7] proposed a numerical model with fixed ends for the beams that are spanning over the damaged columns to calculate the compressive arch action resistance. The numerical resistance predicted by the proposed model was reasonably accurate. Feng Fu [8] simulated the three- dimensional load redistribution mechanisms of different recorded collapses using three-dimensional finite element models with ABAQUS. The simulations were in good agreement with the recorded failures. Forni et al. [9] described a micro model using LS-DYNA to examine the multi-hazard effects of fire and blast on steel columns. Bao et al. [10] generated macro models to investigate the resistance of $\mathrm{RC}$ frame subassemblies, with seismic and non-seismic detailing, to progressive collapse. Seismic detailed frames performed better. Izzuddin et al. [11] examined the column removal dynamic effects on 
the structures by proposing an equivalent nonlinear static energy-based approach that compensates the dynamic effects of column removal. Using LS-DYNA software, Husain et al. [12] numerically investigated resistance of post-tensioned concrete beam-column assemblies to progressive collapse due to middle column failure. It was found that using prestressing tendons with a straight profile is an efficient means of upgrading the resistance of RC beams spanning over the removed column. El-Ariss and Elkholy [13] and Elkholy and El-Ariss [14, 15] described a technique and a numerical procedure for mitigating RC continuous beams to prevent potential progressive collapse resulting from interior column failures. The technique proposed the use of external unbounded straight cables attached to the beam at anchorage locations and deviator points, without being posttensioned. The proposed technique increased the beam ultimate loadcarrying capacity and energy dissipation capability.

To experimentally study the behaviour of RC assemblages, Qian et al. [16] examined the performance of three unbonded posttensioned (PT) beam-column sub-assemblage specimens subjected to interior column removal. Damages happened away from the side columns and concentrated at the beam ends in the vicinity of the middle joint. These damages were attributed to the tendon profile and lack of PT detailing. Peng et al. $[17,18]$ tested the resistances of old RC flat-plate buildings to progressive collapse due to dynamic removal of supporting columns. The building lacked slab integrity reinforcement and was loaded with different load intensities until failure. It was observed that these buildings were susceptible to progressive collapse subsequent to a dynamic column removal and that they were at higher risk of collapsing when an internal column was removed.

To experimentally and analytically estimate the progressive collapse resistance, Keyvani and Sasani [19, 20] performed a full scale experiment on a posttensioned parking garage structure by removing an interior column through explosion and developed SAP2000 numerical models to simulate the behaviour of the structure. The formation of compressive membrane action led to an increase in the flexural capacity of garage slab. The numerical models did not adequately predict the behaviour of the structure and a nonlinear finite element analysis was suggested. Al-Salloum et al. [21] experimentally and analytically studied the effectiveness of using a mitigating scheme of bolted steel plates on the precast beam-column connection behaviour when subjected to progressive collapse. They concluded that linear elastic analysis might not be suitable to simulate the behaviour of structures with large deformations and that nonlinear finite element analysis would be essential.

Even though many of the numerical and experimental studies found in this literature search have recommended that buildings should have basic characteristics like energy absorption, continuity, and ductility to avert progressive collapse, few of them offered any quantitative numerical models, for evaluating the potential for progressive collapse, in which the "directly go-to" model parameters that significantly affect the numerical results and substantially reduce the computational time were identified. This study is presented to fill in this gap by identifying these parameters when optimizing the accuracy of the numerical outcomes generated by the proposed fibre-based numerical model.

\section{Fibre Element-Based Numerical Model}

A complete inelastic finite element analysis of structures is very intensive computationally and time overwhelming. To reduce the time and effort and to account for material and geometric nonlinearities, fibre element-based software, such as SeismoStruct [22] is used to model and analyse structures subjected to large deformations as a result of column removal. The structural members are modelled using beam-column element and material and geometrical nonlinear properties are accounted for using the plastic hinge or spread-of-plasticity. The analysis is carried out by applying displacement-controlled nonlinear static push-down at the location of failed column to simulate the removal of the column and to predict the progressive collapse of the structure. The load is applied in increment and stresses and strains are calculated for each element are compared with some material performance criteria such as concrete cracking and crushing, steel yielding, and fracture to determine whether or not the element has failed. If the performance criteria are not reached, the analysis continues and the applied load is incrementally increased until a performance criterion is reached and the element fails. Following the element failure, the load is kept at its current level while the stiffness is modified to account for the material and geometric nonlinearities during the analysis. In this analysis the load is kept at the same level and calculations are continued to ensure no more elements have failed. Then the load is increased and 
iterations are carried out to calculate the stresses, strains, and deformations after each load increment and the analysis stops when a sudden failure occurs. A flowchart representing the progressive collapse analysis is shown if Figure 1. Using finite element packages that are based on fibre element approach, such as SeismoStruct, allows the use of both material inelasticity and geometric nonlinearities to predict large displacement behaviour and strength of framed structures.

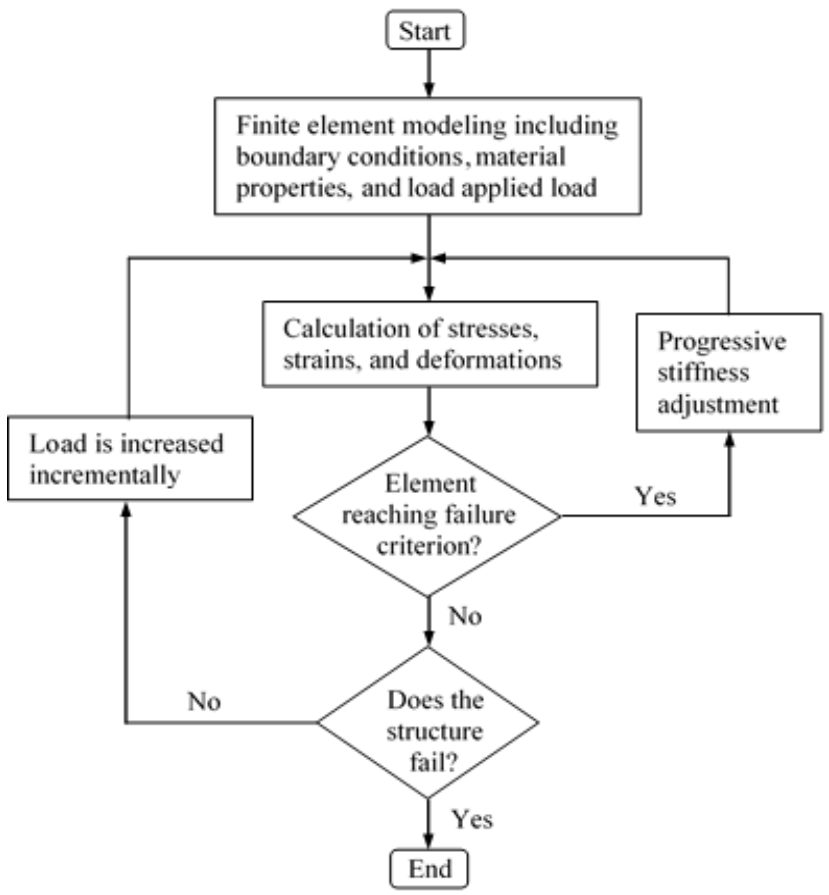

Fig. 1. Flow chart of progressive collapse analysis.

\section{Verification of Proposed Fibre Element-Based Model}

To verify the proposed numerical model for RC frames, the sub assemblage tested by Qiang et al. [23] was modelled and analysed. The test was performed to investigate whether a suggested novel kinked rebar configuration would enhance multiple resistances to seismic and progressive collapse of $\mathrm{RC}$ frames. The test setup and configuration are shown in Figure 2 and in Table 1 (specimen RCB). The fibre element-based software, SeismoStruct, was used in this study to generate the optimal model with the best simulation of the test behaviour. In addition, SeismoStruct provides different element classes that belong to the same element type to define the member. By making use of these element types and classes, the model can accurately represent the structural member as well as different boundary conditions. The cross-section of the members is modelled by separate individual fibre elements (typically 100-150) representing concrete and steel; the discretization of a typical RC cross-section is depicted in Figure 2b. Within the cross-section, the grid number and mesh size are automatically generated by the program based on the change in the compressive strengths of concrete due to confinement of the section. The cross-section stress-strain state is obtained by integrating the nonlinear stress-strain model of the individual fibres. The spread of plasticity along the element derives from an inelastic cubic formulation with Gauss points to use for numerical integration of the equilibrium equations. At the beginning, the default material models provided by the software were utilized and the obtained numerical behaviour was not in agreement with the test results. The material models were changed and adjusted until the best simulation was achieved and the model was verified when the numerical behaviour was accurate enough and almost matched the test result, as shown in Figure 2c.

After achieving the most accurate numerical behaviour, the model application validity to other RC assemblage frames with different dimensions, material properties, and reinforcements was further examined to identify and optimize the critical 
and directly go-to model parameters that significantly affect the numerical results and substantially reduce the computational time.

To do that the test RC frame sub assemblage dimensions and material properties were changed and an extensive and modification to the model parameters was carried out to determine the most critical and dominant parameters to go-to in any new model generation to reach numerical results within a range of $\pm 15 \%$ of the test frame results. Further adjustment of these significant parameters would lead to more accurate and optimal numerical results. This is in Figure 2c by the upper and lower numerical curves, that were produced by directly going to these dominant model parameters, and by the more accurate numerical curve that was obtained after tuning these key parameters. In this study parameters such as number of elements, Gauss-Lobatto integration sections, steps of loading, and material properties were found to be the most influential parameters on the numerical outcomes.

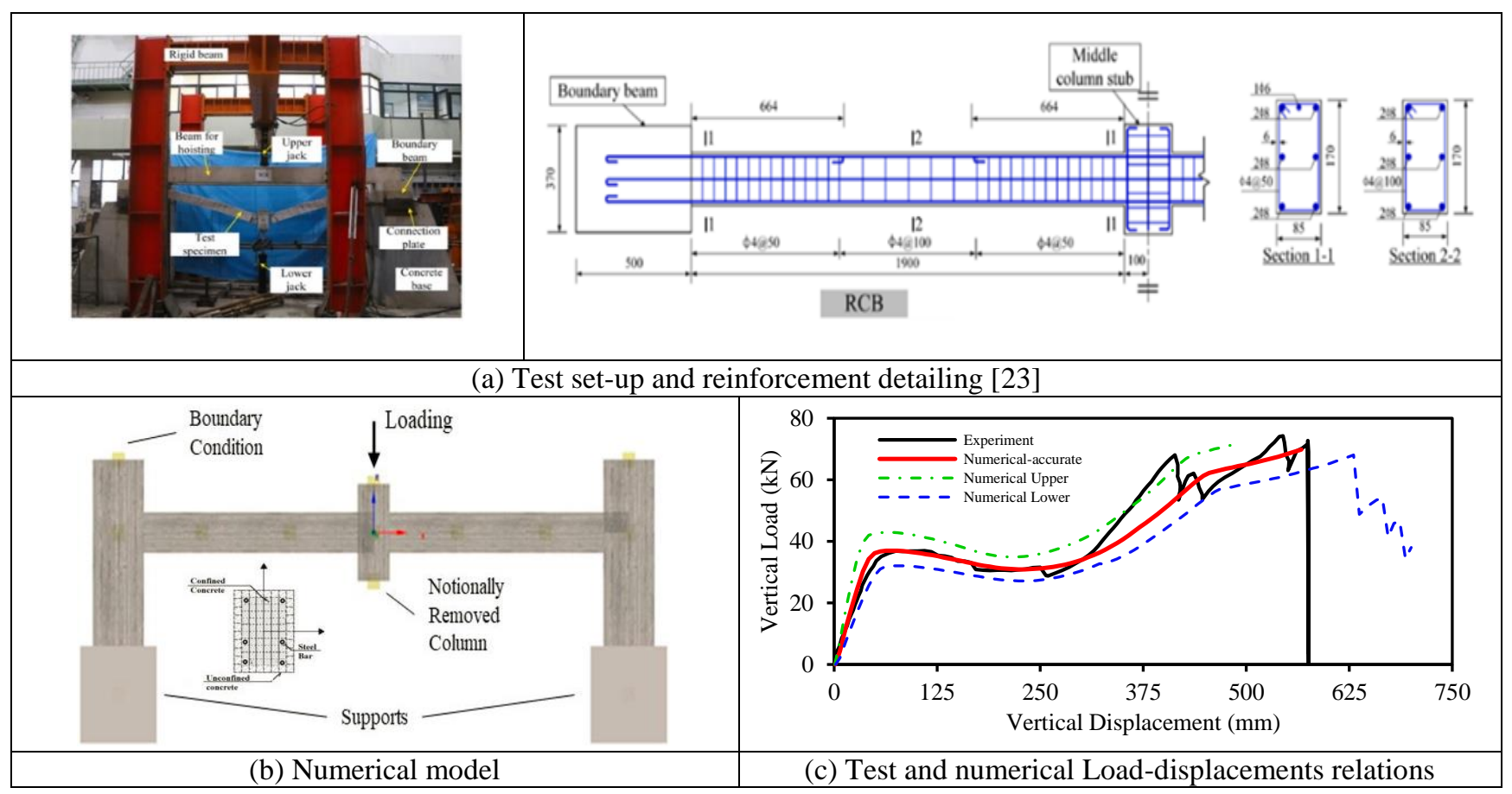

Fig. 2: Verification of proposed model.

\section{Parametric Studies on Progressive Collapse Behaviour of RC Sub Assemblages}

To validate the application of the same numerical model described above to different RC structures, the parametric study in this section concentrated on basic parameters that are important in the design of RC structures such reinforcement ratio, beam and column dimensions, beam spans, concrete strength, steel reinforcement strength, and boundary conditions while utilizing the few "directly go-to" model parameters, identified in the previous section, and using all other parameters as default to optimize and produce an accurate behaviour of the considered sub assemblage structure with less computational time and effort. Therefore, with the verified proposed numerical model, parametric studies was carried out on nine RC frame sub assemblage specimens to check the application validity of the model. The specimen names, dimensions, material properties, and reinforcement ratios, and their references are given in Table 1.

Alogla et al. [24] proposed a mitigating scheme to enhance the progressive collapse resistance of RC structures by providing additional steel in the middle. Three specimens SS-1, SS-2, and SS-3 were tested. The data for each specimen is provided in Table 1. Two of the specimens tested by Yu and Tan [25], specimens F1 and F2 shown in Table 1, were designed with special detailing techniques to increase the catenary action capacity at large deformations. The two specimens had an additional reinforcement layer at the mid height of beam section with partly debonded bottom 
reinforcing bars in the joint region. The specimens had different reinforcement ratios as shown in Table 1. Specimen F2 had a distinct detailing that included setting partial hinges at a distance equal to the beam depth away from the joint interface. The effects of transverse beams reinforced concrete frames resistance to progressive collapse were experimentally investigated by Rashidian et al. [26]. Specimen 2D shown in Table 1 was considered in this parametric study. Kang and Tan [27] presented an experimental study on four precast concrete sub assemblage specimens with the bottom reinforcement has either lap-splice or $90^{\circ}$ bend of in the beam-column joint. Two specimens, IF-L and IF-B listed in Table 1, were considered in this study. To investigate that effects of different concrete strengths and span-to-depth ratios on progressive collapse resistance, Deng et al. [28] tested six RC sub assemblage frames. One specimen, HSC-8, was considered in this study.

It is evident in Figure 3 that the proposed numerical model predicted fairy accurately the behaviours of the test specimens, listed in Table 1, by optimizing just few model parameters such as number of elements, number of integration points, boundary conditions. Therefore, the validity of the application of proposed model to other RC frame structures is verified.

Table 1: Brief description of Referenced experiments used for validating the numerical model application.

\begin{tabular}{|c|c|c|c|c|c|c|c|c|c|c|c|c|c|c|}
\hline \multicolumn{15}{|c|}{ Specimen Description } \\
\hline Serial & Ref. & $\begin{array}{l}\text { Specimen } \\
\text { name }\end{array}$ & Scale & $\begin{array}{c}\text { Clear } \\
\text { Span, } \\
\text { L_s } \\
(\mathrm{mm})\end{array}$ & $\begin{array}{l}1 \_\mathrm{b} \\
(\mathrm{mm})\end{array}$ & $\begin{array}{l}\mathrm{h} \_1 \\
(\mathrm{~mm})\end{array}$ & $\begin{array}{l}\mathrm{h} \_2 \\
(\mathrm{~mm})\end{array}$ & $\begin{array}{c}\text { Beam } \\
\text { cross- } \\
\text { section, } \\
\text { H_b } \times \text { B } \\
\left(\mathrm{mm}^{2}\right)\end{array}$ & 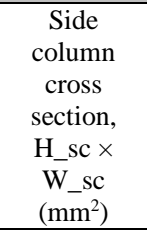 & $\begin{array}{c}\text { Middle } \\
\text { column } \\
\text { cross } \\
\text { section, } \\
\text { H_mc } \times \\
\text { W_mc } \\
\left(\mathrm{mm}^{2}\right)\end{array}$ & $\begin{array}{c}\text { Top } \\
\text { Reinf. } \\
\text { Ratio } \\
\text { at } \\
\text { Sectio } \\
\text { n B-B } \\
(\%) \\
\end{array}$ & $\begin{array}{l}\text { Bottom } \\
\text { Reinf. } \\
\text { Ratio at } \\
\text { Section } \\
\text { B-B } \\
(\%)\end{array}$ & $\begin{array}{l}f_{c}^{\prime}, \\
M P a\end{array}$ & $f_{y}, M P a$ \\
\hline 1 & {$[23]$} & $\mathrm{RCB}$ & $1 / 3$ & 1900 & 664 & 185 & 185 & $170 \times 85$ & $\mathrm{~N} / \mathrm{A} \times 500$ & $200 \times 200$ & 0.92 & 0.72 & 43.1 & 387 \\
\hline 3 & \multirow[t]{2}{*}{ [24] } & SS-2 & $1 / 2$ & 2650 & 900 & 450 & 450 & $250 \times 150$ & $400 \times 400$ & $250 \times 250$ & 0.72 & 0.48 & 26.8 & 510 \\
\hline 4 & & SS-3 & $1 / 2$ & 2650 & 900 & 450 & 450 & $250 \times 150$ & $400 \times 400$ & $250 \times 250$ & 0.72 & 0.48 & 27.5 & 510 \\
\hline 5 & \multirow{2}{*}[25]{} & F1 & $1 / 2$ & 2750 & 1000 & 1100 & 1050 & $250 \times 150$ & $250 \times 250$ & $250 \times 250$ & 0.82 & 1.24 & 29.7 & $520 / 488$ \\
\hline 6 & & $\mathrm{~F} 2$ & $1 / 2$ & 2750 & 1000 & 1100 & 1050 & $250 \times 150$ & $250 \times 250$ & $250 \times 250$ & 0.82 & 1.24 & 26.7 & $520 / 488$ \\
\hline 7 & {$[26]$} & $2 \mathrm{D}$ & $3 / 10$ & 1400 & 500 & 520 & 820 & $140 \times 200$ & $200 \times 200$ & $200 \times 200$ & 0.62 & 0.41 & 26 & 530 \\
\hline 8 & [27] & IF-L & $1 / 2$ & 2750 & 1000 & 1325 & 1025 & $300 \times 150$ & $250 \times 250$ & $250 \times 250$ & 0.88 & 0.59 & 26.9 & 593.7 \\
\hline
\end{tabular}

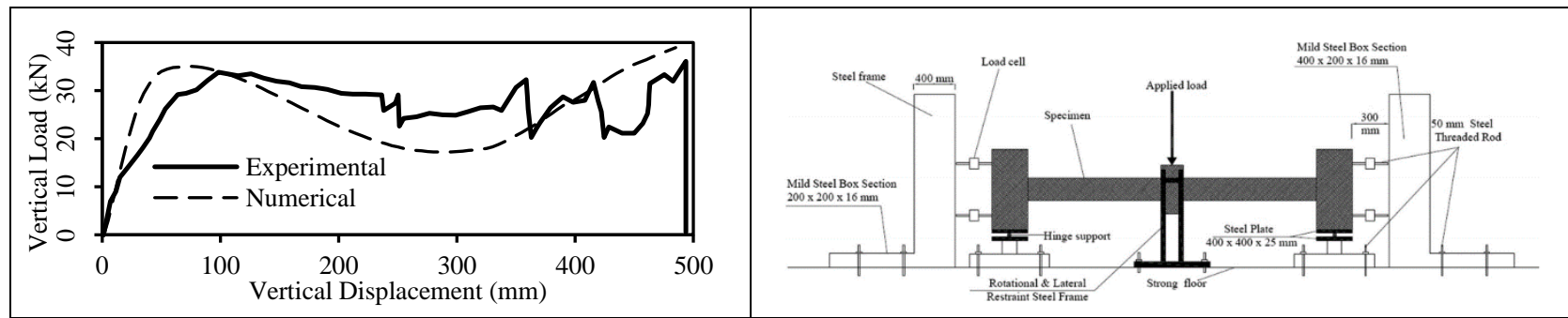

(a) Numerical and test behaviour of specimen SS-1 [24]
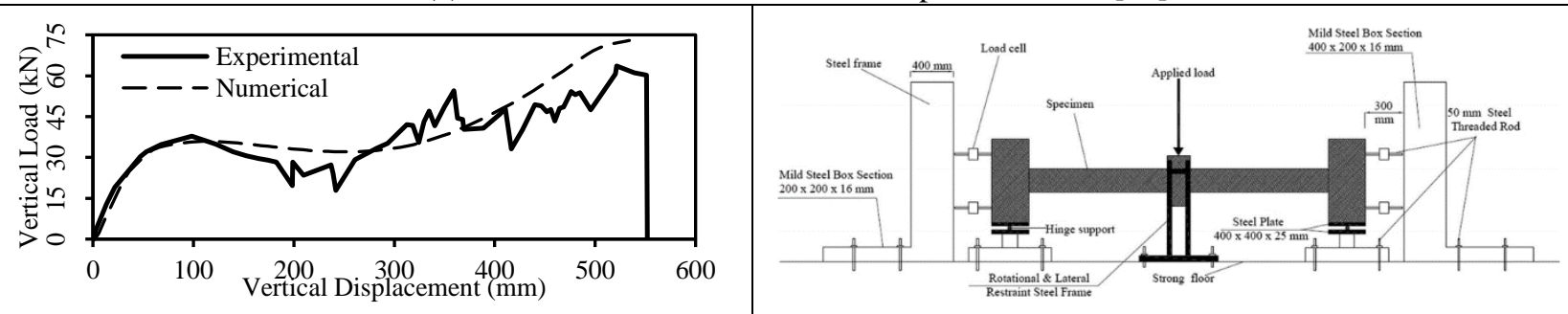

(b) Numerical and test behaviour of specimen SS-2 [24] 

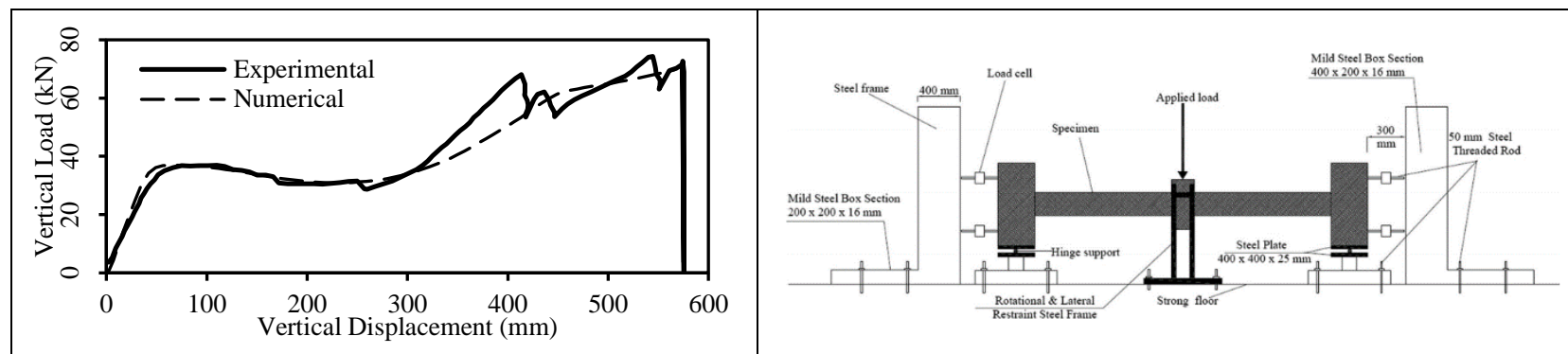

(c) Numerical and test behaviour of specimen SS-3 [24]
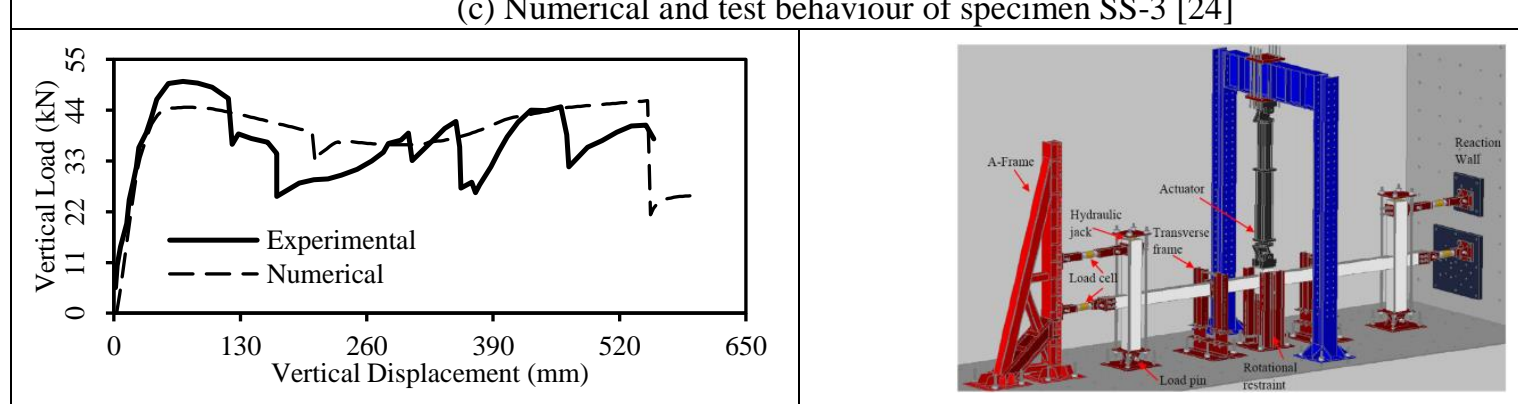

(d) Numerical and test behaviour of specimen F-1 [25]
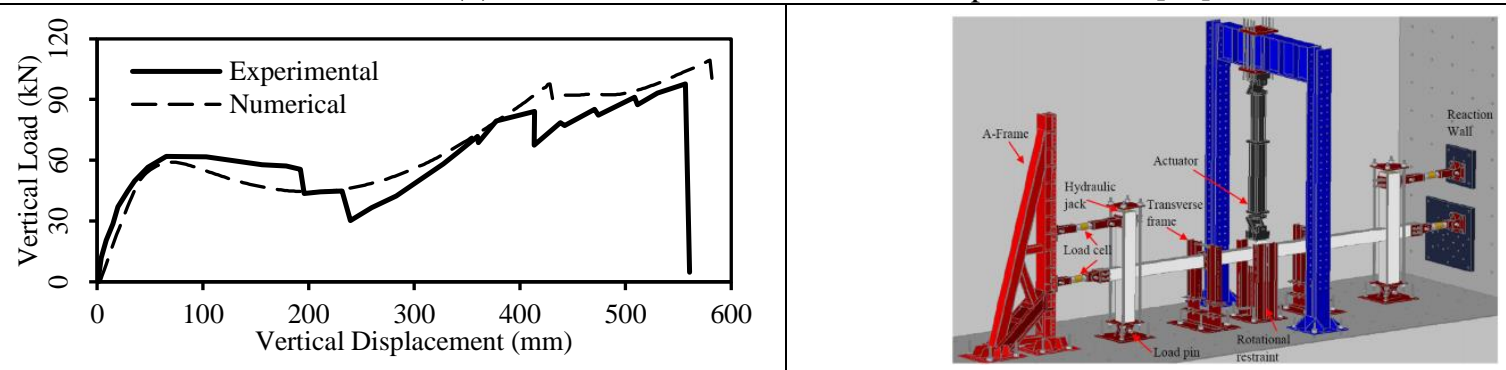

(e) Numerical and test behaviour of specimen F-2 [25]
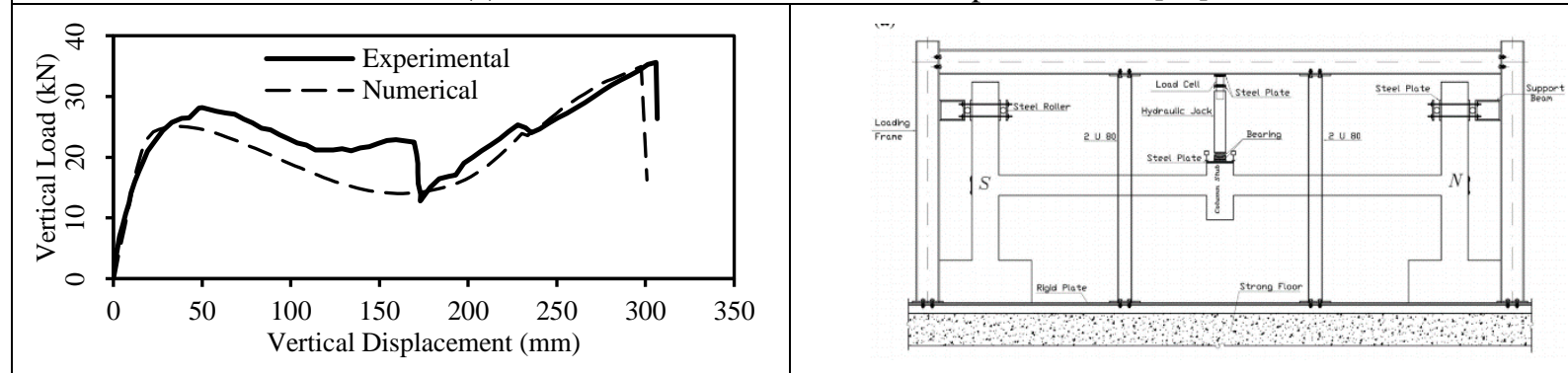

(f) Numerical and test behaviour of specimen 2D [26]
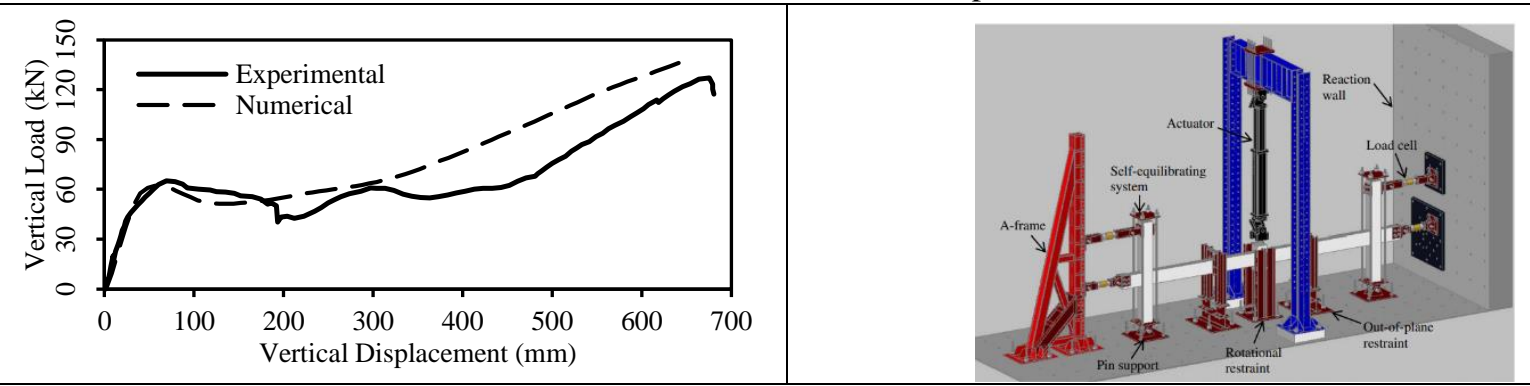

(g) Numerical and test behaviour of specimen IF-L [27] 


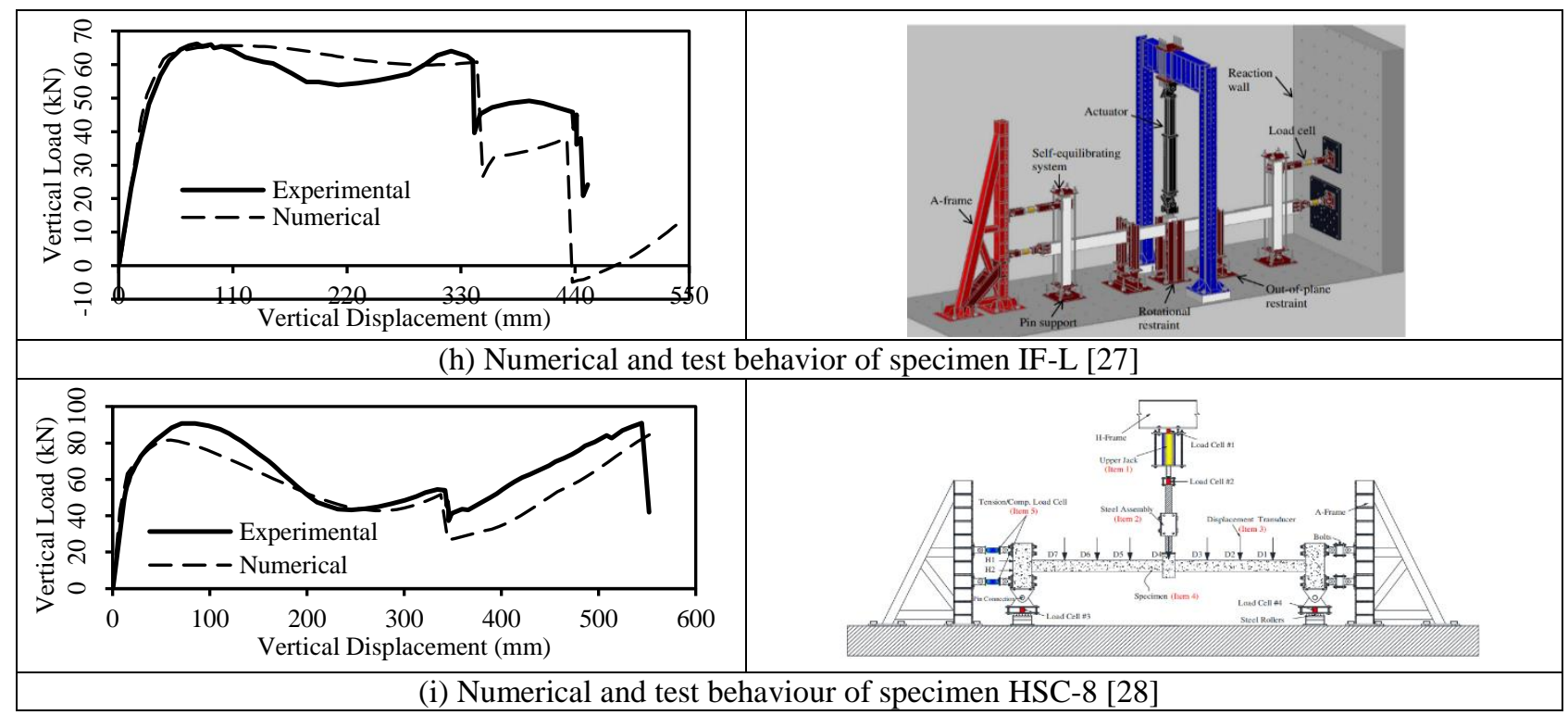

Fig. 3: Verification of proposed model.

\section{Conclusion}

This paper discusses an efficient numerical model to accurately predict the progressive collapse behaviour of precast $\mathrm{RC}$ frame sub assemblages. The model is based on the fibre element approach and can be used to simulate frame sub assemblages with different member cross-section dimensions, lengths, material strengths, and boundary conditions.

With the validation of numerical model, parameters such as number of elements, Gauss-Lobatto integration sections, steps of loading, and material properties were identified in this study as "directly go-to" key model parameters to focus on and tune when generating the model to optimize the numerical outcomes. Focusing on these model parameters, while keeping all other parameters as default, minimizes the effort to generate a reliable and efficient model and also reduces the computational time. The parametric study in this paper confirms the validity of the proposed model application to other RC frame sub assemblages with different basic factors that are important in the design such reinforcement ratio, beam and column dimensions, beam spans, concrete strength, steel reinforcement strength, and boundary conditions. The parametric study showed that when optimising the identified "directly go-to" key model parameters, the predicted numerical behaviour of the structures considered were in good agreement with the test results.

The proposed fibre element based model can be utilized as reliable means for the analysis of RC structures subjected to progressive collapse due to column removal scenario because it balances between the accuracy of numerical outcomes and computational efficacy.

\section{References}

[1] M. Byfield, W. Mudalige, C. Morison and E. Stoddart, "A review of progressive collapse research and regulations," Proceedings of the Institution of Civil Engineers-Structures and Buildings, vol. 167, no. 8, pp. 447-456, 2014.

[2] J. M. Adam, F. Parisi, J. Sagaseta and X. Lu., "Research and practice on progressive collapse and robustness of building structures in the 21st century," Engineering Structures, vol. 173, pp. 122-149, 2018.

[3] H. Wang, A. Zhang, Y. Li and W. Yan, "A review on progressive collapse of building structures," The Open Civil Engineering Journal, vol. 8, no. 1, 2014.

[4] B. Abdelwahed, "A review on building progressive collapse, survey and discussion," Case Studies in Construction Materials, vol. 11, 2019.

[5] "General Services Administration (GSA), Progressive Collapse Analysis and Design Guidelines for New Federal Office Buildings and Major Modernization Projects," 2013. 
[6] "Design of Building to Resist Progressive Collapse," 2010.

[7] X. Lu, K. Lin, C. Li and Y. Li, "New analytical calculation models for compressive arch action in reinforced concrete structures," Eng. Struct., vol. 168, p. 721-735, 2018.

[8] F. Fu, "Structural Analysis and Design to Prevent Disproportionate Collapse," CRC Press, 2018.

[9] D. Forni, B. Chiaia and E. Cadoni, "Blast effects on steel columns under fire conditions," Journal of Constructional Steel Research, vol. 136, p. 1-10, 2017.

10] Y. Bao, K. Sashi, E. Sherif and H. Lew, "Macro model-based simulation of progressive collapse: RC frame structures," Journal of Structural Engineering, vol. 134, no. 7, 2008.

[11] B. Izzuddin, A. Vlassis, A. ELghazouli and D. Nethercot, "Progressive collapse of multi-storey buildings due to sudden column loss - Part I: Simplified assessment framework," Eng. Struct., vol. 30, p. 1308-1318, 2008.

[12] M. Husain, J. Yu, B. Osman and J. Ji, "Progressive collapse resistance of post-tensioned concrete beam-column assemblies under a middle column removal scenario," Journal of Building Engineering, vol. 34, p. 101945, 2021.

[13] B. El-Ariss and S. Elkholy, "Scheme for beam progressive collapse mitigation," International Journal of Structural Engineering, 9(3), pp.175-190, 2018.

[14] S. Elkholy and B. El-Ariss, "Improving the robustness of reinforced concrete framed structures under sudden column losses," International," Journal of Protective Structures, 7(2), pp.282-300, 2016.

[15] S. Elkholy and B. El-Ariss, "Progressive collapse evaluation of externally mitigated reinforced concrete beams." Engineering Failure Analysis, 40, 33-47, 2014.

[16] K. Qian, Y. Liu, T. Yang and B. Li, "Progressive collapse resistance of posttensioned concrete beam-column subassemblages with unbonded posttensioning strands," Journal of Structural Engineering, vol. 144, no. 1, 2018.

[17] Z. Peng, S. L. Orton, J. Liu and Y. Tian, "Experimental study of dynamic progressive collapse in flat-plate buildings subjected to exterior column removal," Journal of Structural Engineering, vol. 143, no. 9, 2017.

[18] Z. Peng, S. L. Orton, J. Liu and Y. Tian, "Experimental study of dynamic progressive collapse in flat-plate buildings subjected to an interior column removal," Journal of Structural Engineering, vol. 144, no. 8, 2018.

[19] L. Keyvani and M. Sasani, "Analytical and experimental evaluation of progressive collapse resistance of a flat-slab posttensioned parking garage," Journal of Structural Engineering, vol. 141, no. 11, 2015. doi:10.1061/(asce)st.1943$541 x .0001279$.

[20] L. Keyvani and M. Sasani, "Response of a Post-Tensioned Floor Following a Column Loss," Special Publication, vol. 309, pp. 1-18, 2016.

[21] Y. A. Al-Salloum, M. A. Alrubaidi, H. M. Elsanadedy, T. H. Almusallam and R. A. Iqbal, "Strengthening of precast RC beam-column connections for progressive collapse mitigation using bolted steel plates," Engineering Structures, vol. 161, pp. 146-160, 2018.

[22] S. SeismoSoft, "A computer program for static and dynamic nonlinear analysis of framed structures," 2007.

[23] H. Qiang, J. Yang, P. Feng and W. Qin, "Kinked rebar configurations for improving the progressive collapse behaviours of RC frames under middle column removal scenarios," Engineering Structures, vol. 211, p. 110425, 2020.

[24] K. Alogla, L. Weekes and L. Augusthus-Nelson, "A new mitigation scheme to resist progressive collapse of RC structures," Construction and Building Materials, vol. 125, pp. 533-545, 2016.

[25] J. Yu and K. H. Tan, "Special detailing techniques to improve structural resistance against progressive collapse," Journal of Structural Engineering, vol. 140, no. 3, 2014.

[26] O. Rashidian, R. Abbasnia, R. Ahmadi and F. M. Nav, "Progressive collapse of exterior reinforced concrete beamcolumn sub-assemblages: Considering the effects of a transverse frame," International Journal of Concrete Structures and Materials, vol. 10, no. 4, 2016.

[27] S. B. Kang and K. H. Tan, "Progressive collapse resistance of precast concrete frames with discontinuous reinforcement in the joint," Journal of Structural Engineering, vol. 143, no. 9, 2017.

[28] X. F. Deng, S. L. Liang, F. Fu and K. Qian, "Effects of high-strength concrete on progressive collapse resistance of reinforced concrete frame," Journal of Structural Engineering, vol. 146, no. 6, 2020. 